\title{
The prognostic role of systemic inflammatory markers on HIV-infected patients with non- Hodgkin lymphoma, a multicenter cohort study
}

Elena Raffetti ${ }^{*}$, Francesco Donato ${ }^{1}$, Filippo Castelnuovo ${ }^{2}$, Nicoletta Ladisa ${ }^{3}$, Giuseppe Paraninfo ${ }^{4}$, Elisa Di Filippo ${ }^{5}$, Daniela Segala ${ }^{6}$, Giuliana Cologni ${ }^{5}$, Alessandra Bandera ${ }^{7}$, Fabio Zacchi $^{8}$, Simona Digiambenedetto ${ }^{9}$, Massimo Di Pietro ${ }^{10}$, Francesco Castellii ${ }^{4}$ Eugenia Quiros-Roldan ${ }^{4}$ and MASTER Cohort

\begin{abstract}
Background: The systemic inflammatory response has been postulated as having prognostic significance in a wide range of different cancer types. We aimed to assess the prognostic role of inflammatory markers on survival in HIVinfected patients with Non-Hodgkin Lymphoma (NHL), and to compute a prognostic score based on inflammatory biomarkers.

Methods: We evaluated data on HIV patients with NLH diagnosis between 1998 and 2012 in a HIV Italian Cohort. Using Cox proportional regression model, we assessed the prognostic role of Neutrophil-Lymphocyte Ratio (NLR), Platelet-Lymphocyte Ratio (PLR), Glasgow Prognostic Score (GPS), modified Glasgow Prognostic Score (mGPS), Prognostic Index (PI), and Prognostic Nutritional Index (PNI). We also computed a risk score equation, assigning patients to a derivation and a validation sample. The area under the curve (AUC) was use to evaluate the predictive ability of this score.

Results: 215 non-Hodgkin lymphoma cases (80.0\% males) with a mean age of 43.2 years were included. Deaths were observed in 98 (45.6\%) patients during a median follow up of 5 years. GPS, mGPS, PI and PNI were independently associated with risk of death. We also computed a mortality risk score which included PNI and occurrence of an AIDS event within six months from NHL diagnosis. The AUCs were $0.69(95 \% \mathrm{Cl} 0.58$ to 0.81$)$ and $0.69(95 \% \mathrm{Cl} 0.57$ to 0.81$)$ at 3 and 5 years of the follow-up, respectively.
\end{abstract}

Conclusions: GPS, mGPS, PI and PNI are independent prognostic factors for survival of HIV patients with NHL.

Keywords: Inflammatory markers, Prognostic score, HIV, Non-Hodgkin lymphoma

\section{Introduction}

Non-Hodgkin Lymphoma (NHL) is one of the most common cancer and cause of death among HIV-infected patients [1-3]. Overall survival is poor and more than half subjects die within five years from NHL diagnosis, although it has improved after the introduction of the combined Antiretroviral Therapy (cART) [2-9].

The International Prognostic Index (IPI) was developed at the beginning of 1990s by the International Non-Hodgkin Lymphoma Prognostic Factors Project to

\footnotetext{
* Correspondence: e.raffetti@unibs.it

${ }^{1}$ Unit of Hygiene, Epidemiology and Public Health, University of Brescia, Brescia, Italy

Full list of author information is available at the end of the article
}

create a prognostic tool for patients with aggressive NHL treated with doxorubicin-containing chemotherapy in the general population [10]. The IPI categorizes patients into low, intermediate and high risk groups based on the baseline characteristics including age, Eastern Cooperative Oncology Group performance status, Lactate Dehydrogenase (LDH) level, Ann Arbor stage, and extranodal involvement. The IPI has also been demonstrated prognostic for lymphomas associated with HIV infection [4].

Tumor microenvironment and inflammatory response have an important role at different stages of tumor development, including initiation, promotion, malignant conversion, invasion and metastasis [11]. Recent studies 
showed that some blood parameters associated with systemic inflammation, i.e. C-Reactive Protein (CRP), white cell, neutrophil and platelet count, and hypoalbuminemia are predictors of survival in patients with primary solid cancers [12]. Various combinations of these factors have been used to derive inflammation-based scores to predict survival of subjects with solid cancers [13-16], such as Glasgow Prognostic Score (GPS), Neutrophil/Lymphocyte Ratio (NLR) and Platelet/Lymphocyte Ratio (PLR).

Few studies have investigated the association between these inflammatory scores and survival in patients with NHL [17-19], none of which in HIV-infected patients, so far.

The aims of this study were: (i) to evaluate the prognostic role of inflammatory markers on survival in HIVinfected patients with NHL and, (ii) to compute a prognostic score based on demographical and clinical variables and inflammatory biomarkers.

\section{Methods}

The Italian MASTER cohort is a hospital-based multicenter, open, dynamic cohort established in the mid1990s with retrospective patients' enrolment since 1986. At present, the cohort includes about 24500 HIVinfected subjects, aged 18 years or older, at eight Infectious Diseases Units throughout Italy. In this work we included HIV-infected patients with a first NHL diagnosis between January 1998 and December 2012. The study design and cancer collection data have been described previously [1].

We retrieved gender, age, country of origin, HIV exposure risk, date of enrolment in the cohort, Hepatitis B Virus (HBV) or/and Hepatitis C Virus (HCV) coinfection and cART at cancer diagnosis from the MASTER electronic database. The following parameters, measured within 6 months from the diagnosis of NHL, were also retrieved: AIDS event occurrence, HIV-RNA, CD4 cell count, CD8 cell count, CRP, albumin, white blood cell, neutrophil, lymphocyte and platelet counts. The inflammatory based prognostic variables GPS, modified Glasgow Prognostic Score (mGPS), NLR, PLR, Prognostic Index (PI), and Prognostic Nutritional Index (PNI) were defined as shown in Table 1.

The study was conducted in accordance with the guidelines of the Declaration of Helsinki and the principles of Good Clinical Practice. Informed consent was obtained according to the standards of the local ethics committees.

\section{Statistical analysis}

The primary outcome of this study was all-cause mortality. The cumulative risk of death was determined from the data of NHL diagnosis to the end of the observation period. The censor date for survival analysis was 31st
Table 1 Inflammation-based prognostic variables

\begin{tabular}{|c|c|c|}
\hline Variables & Criteria & Score \\
\hline \multirow[t]{4}{*}{ GPS } & $\begin{array}{l}\text { C-Reactive Protein } \leq 1.0 \mathrm{mg} / \mathrm{dl} \text { and } \\
\text { albumin } \geq 3.5 \mathrm{~g} / \mathrm{dl}\end{array}$ & 0 \\
\hline & $\begin{array}{l}\text { C-Reactive Protein }>1.0 \mathrm{mg} / \mathrm{dl} \text { and } \\
\text { albumin } \geq 3.5 \mathrm{~g} / \mathrm{dl}\end{array}$ & 1 \\
\hline & $\begin{array}{l}\text { C-Reactive Protein } \leq 1.0 \mathrm{mg} / \mathrm{dl} \text { and } \\
\text { albumin }<3.5 \mathrm{~g} / \mathrm{dl}\end{array}$ & \\
\hline & $\begin{array}{l}\text { C-Reactive Protein }>1.0 \mathrm{mg} / \mathrm{dl} \text { and } \\
\text { albumin }<3.5 \mathrm{~g} / \mathrm{dl}\end{array}$ & 2 \\
\hline \multirow[t]{3}{*}{ mGPS } & C-Reactive Protein $\leq 1.0 \mathrm{mg} / \mathrm{dl}$ & 0 \\
\hline & $\begin{array}{l}\text { C-Reactive Protein }>1.0 \mathrm{mg} / \mathrm{dl} \text { and } \\
\text { albumin } \geq 3.5 \mathrm{~g} / \mathrm{dl}\end{array}$ & 1 \\
\hline & $\begin{array}{l}\text { C-Reactive Protein }>1.0 \mathrm{mg} / \mathrm{dl} \text { and } \\
\text { albumin }<3.5 \mathrm{~g} / \mathrm{dl}\end{array}$ & 2 \\
\hline \multirow[t]{3}{*}{ NLR } & neutrophil coun/lymphocyte count $<1 / 3$ & 0 \\
\hline & neutrophil count/lymphocyte count 3-5/1 & 1 \\
\hline & neutrophil count/lymphocyte count $\geq 3 / 1$ & 2 \\
\hline \multirow[t]{3}{*}{ PLR } & platelet count/lymphocyte count <150/1 & 0 \\
\hline & platelet count/lymphocyte count 150-300/1 & 1 \\
\hline & platelet count/lymphocyte count >300/1 & 2 \\
\hline \multirow[t]{4}{*}{ PI } & $\begin{array}{l}\text { C-Reactive Protein } \leq 1 \mathrm{mg} / \mathrm{dl} \text { and white } \\
\text { blood cell count } \leq 11,000 / \mu \mathrm{l}\end{array}$ & 0 \\
\hline & $\begin{array}{l}\text { C-Reactive Protein } \leq 1 \mathrm{mg} / \mathrm{dl} \text { and white } \\
\text { blood cell count }>11,000 / \mu \mathrm{l}\end{array}$ & 1 \\
\hline & $\begin{array}{l}\text { C-Reactive Protein }>1 \mathrm{mg} / \mathrm{dl} \text { and white } \\
\text { blood cell count } \leq 11,000 / \mu \mathrm{l}\end{array}$ & \\
\hline & $\begin{array}{l}\text { C-Reactive Protein }>1 \mathrm{mg} / \mathrm{dl} \text { and white } \\
\text { blood cell count }>11,000 / \mu \mathrm{l}\end{array}$ & 2 \\
\hline \multirow[t]{4}{*}{ PNI } & albumin $(\mathrm{g} / \mathrm{dl}) \times 10+0.005 \times$ total & 0 \\
\hline & lymphocyte count $(/ \mu \mid) \geq 45$ & \\
\hline & albumin $(\mathrm{g} / \mathrm{dl}) \times 10+0.005 \times$ total & 1 \\
\hline & lymphocyte count $(/ \mu \mid)<45$ & \\
\hline
\end{tabular}

Abbreviations: GPS Glasgow Prognostic Score, mGPS modified Glasgow Prognostic Score, NLR Neutrophil/Lymphocyte Ratio, PLR Platelet/Lymphocyte Ratio, PI Prognostic Index, PNI Prognostic Nutritional Index.

December 2012. The observation period ended either on 31st December 2012, or at last follow-up visit or death, whichever occurred first. Patients lost to follow-up contributed to the time at risk until last visit.

At first, the associations of each prognostic variable with all-cause mortality were tested by univariate and multivariate analysis using Cox proportional hazard models. Gender, age at cancer diagnosis, intravenous drug use, AIDS defining event, HBV and/or HCV coinfection, cART, CD4 cell count, HIV-RNA undetectable were included as covariates. The results were expressed as Hazards Ratios (HRs), their 95\% Confidence Intervals (95\% CIs), and p-values according to Wald test. Due a few missing data in GPS, mGPS, PLR, PI, and PNI, the Cox proportional hazard regression models were adjusted by stabilized inverse probability weights with 
missing data in prognostic variables considered missing at random [20]. In order to compare the fitness of the model with and without the inflammatory variables, we used the log-likelihood ratio test.

The Area Under the Receiver Operating Characteristic (ROC) Curve (AUC) was used to assess the predictive accuracy of each prognostic variable. As sensitivity analyses, we assessed the consistency of the prognostic role of inflammatory variables in subjects who underwent cART at NHL diagnosis.

Non-linear relationships between continuous prognostic variables and risk of death were assessed by Cox regression models with spline terms of the prognostic variables [21]. We used the Akaike's information criterion [22] to assess fitting of models with linear and nonlinear terms and to choose the number of spline knots.

Subsequently, we derived a risk score of mortality on the basis of the inflammatory, demographic and clinical variables. To this end, the patients were randomly divided into two subgroups by split-sample technique: (i) derivation subgroup including $70 \%$ of subjects, and (ii) validation subgroup, including $30 \%$ of subjects. In the derivation sample, a Cox proportional regression model was used to evaluate the association between baseline factors and risk of death, using a cut-off of minimal 10 events per variable for first selection of variables. Gender, age at cancer diagnosis, intravenous drug use, AIDS defining event, $\mathrm{HBV}$ and/or $\mathrm{HCV}$ co-infection, cART, CD4 cell count, HIV-RNA undetectable and PNI were included. Bootstrapping with 1000 replications was performed to check the stability of variables included in the final models. Linear prediction equations, representing the risk scores, were derived from the final model. For visualization purposes, three risk groups were created according to tertiles of the risk scores distribution in the derivation sample. Cumulative incidence rates of mortality among these three groups were compared by the Kaplan-Meier methods and tested with the log-rank test for trend in the derivation sample. In the derivation and the validation sample the AUC was used to assess the predictive accuracy of the risk scores.

The selection of variables for fitting the most parsimonious models was performed using a backward stepwise procedure, with $\mathrm{p}=0.20$ for retaining each variable in the model. A graphical check on each regressor did not detect major departures from the proportional hazard assumption of the model.

All the statistical tests were two-sided, assumed a level of significance of 0.05 and were performed using Stata version 12.0 (StataCorp, College Station, TX, USA).

\section{Results}

A total of 215 non-Hodgkin lymphoma cases were included. They had a mean age of 43.2 years at time of
NHL diagnosis (Standard Deviation, SD $=9.0$ ) and most of them were males $(80.0 \%)$. The characteristics of the patient population at NHL diagnosis are shown in Table 2. Most of them were assuming cART and plasmatic HIV-RNA was positive $(>37 \mathrm{cp} / \mathrm{ml})$. More than half patients had severe immunodeficiency with CD4 cell count less than $<200$ cells $/ \mathrm{mm} 3$.

After a median follow up of 2 years (ranging from 2 days to 13.9 years), 18 patients (8.4\%) were lost and 98 $(45.6 \%)$ died. The median survival was 9.3 years. At 1, 3 and 5 years, cumulative risk of death was $34.1 \%, 44.3 \%$ and $45.7 \%$, respectively.

\section{Prognostic role of inflammation-based prognostic variables}

Table 3 describes the distribution of inflammatory markers and the association between each of them and risk of death using Cox regression models. Median time

Table 2 Demographical and clinical features at non-Hodgkin lymphoma diagnosis

\begin{tabular}{|c|c|c|}
\hline Variables & Categories & n (\%) \\
\hline Total & & 215 \\
\hline Gender & Male & $172(80.0)$ \\
\hline \multirow[t]{4}{*}{ Age (years) } & $<35$ & $31(14.4)$ \\
\hline & $35-49$ & $136(63.3)$ \\
\hline & $\geq 50$ & $48(22.3)$ \\
\hline & Mean (SD) & $43.2(9.0)$ \\
\hline \multirow[t]{3}{*}{ Period of Diagnosis } & 1998-2002 & $71(33.0)$ \\
\hline & 2003-2007 & $88(40.9)$ \\
\hline & 2008-2012 & $56(26.1)$ \\
\hline IDU & Yes & $96(42.8)$ \\
\hline Migrants & Yes & $28(8.7)$ \\
\hline Previous AIDS defining event & Yes & $81(37.7)$ \\
\hline HBV or/and HCV co-infection & Yes & $111(51.6)$ \\
\hline CART & Yes & $172(80.0)$ \\
\hline \multirow[t]{3}{*}{ CD4 cell count, cell/mm3 } & $<200$ & $104(54.2)$ \\
\hline & $\geq 200$ & $88(45.8)$ \\
\hline & Mean (SD) & $275.9(235.3)$ \\
\hline \multirow[t]{3}{*}{ CD4/CD8 Ratio } & $<1$ & $158(89.3)$ \\
\hline & $\geq 1$ & $19(10.7)$ \\
\hline & Mean (SD) & $0.46(0.50)$ \\
\hline \multirow[t]{3}{*}{ HIV-RNA, copies/mL } & Undetectable & $49(26.1)$ \\
\hline & Positive & $139(73.9)$ \\
\hline & Mean $(S D)^{*}$ & 113208.8 ( 310601.3$)$ \\
\hline \multirow{2}{*}{$\begin{array}{l}\text { Status at the end } \\
\text { of the follow-up }\end{array}$} & Alive & $117(54.4)$ \\
\hline & Dead & 98 (45.6) \\
\hline
\end{tabular}

Abbreviations: SD Standard Deviation, IDU Intravenous Drug Use, HBV Hepatitis B Virus, HCV Hepatitis $C$ Virus, CART combined Antiretroviral Therapy, *In subjects with positive HIV-RNA. 
Table 3 Univariate and multivariate Cox regression models for each inflammatory prognostic variable

\begin{tabular}{|c|c|c|c|c|c|c|c|c|}
\hline \multirow[t]{2}{*}{ Variables } & \multirow[t]{2}{*}{ Category $\$$} & \multirow[b]{2}{*}{ n (\%) } & \multirow[b]{2}{*}{$\mathbf{n}$} & \multicolumn{2}{|c|}{ Univariate model } & \multirow[b]{2}{*}{$\mathbf{n}$} & \multicolumn{2}{|c|}{ Multivariate model } \\
\hline & & & & HR $(95 \% \mathrm{Cl})$ & $P$ value & & HR $(95 \% \mathrm{Cl})^{\pi}$ & $P$ value \\
\hline \multirow[t]{4}{*}{ GPS* } & 0 & $20(25.3)$ & 79 & Ref & & 65 & Ref & \\
\hline & 1 & $42(53.2)$ & & $1.82(0.49-6.69)$ & NS & & $1.91(0.45-7.65)$ & NS \\
\hline & 2 & $17(21.5)$ & & $4.39(1.19-16.2)$ & 0.026 & & $4.78(1.15-19.77)$ & 0.031 \\
\hline & Available & 79 (36.7) & & & & & & \\
\hline \multirow[t]{4}{*}{ mGPS* } & 0 & $24(30.4)$ & 79 & Ref & & 65 & Ref & \\
\hline & 1 & $38(48.1)$ & & $2.01(0.61-7.00)$ & NS & & $2.07(0.61-7.01)$ & NS \\
\hline & 2 & $17(21.5)$ & & $4.46(1.36-14.6)$ & 0.013 & & $4.35(1.16-16.36)$ & 0.029 \\
\hline & Available & 79 (36.7) & & & & & & \\
\hline \multirow[t]{5}{*}{ NLR } & 0 & $129(67.2)$ & 192 & Ref & & & & \\
\hline & 1 & $32(16.7)$ & & $1.31(0.74-2.30)$ & NS & & & \\
\hline & 2 & $31(16.1)$ & & $1.48(0.84-2.61)$ & NS & & & \\
\hline & Mean (SD) & $2.92(2.79)$ & & & & & & \\
\hline & Available & $192(89.3)$ & & & & & & \\
\hline \multirow[t]{5}{*}{ PLR } & 0 & $97(48.3)$ & 199 & Ref & & & & \\
\hline & 1 & 67 (33.3) & & $1.16(0.71-1.90)$ & NS & & & \\
\hline & 2 & $37(18.4)$ & & $1.58(0.88-2.84)$ & NS & & & \\
\hline & Mean (SD) & $193.7(135.1)$ & & & & & & \\
\hline & Available & 199 (92.6) & & & & & & \\
\hline \multirow[t]{4}{*}{$\mathrm{PI}^{*}$} & 0 & $29(31.9)$ & 91 & Ref & & 77 & Ref & \\
\hline & 1 & $60(65.9)$ & & $3.33(1.12-9.93)$ & 0.030 & & $3.25(1.06-9.94)$ & 0.039 \\
\hline & 2 & $2(2.2)$ & & $3.98(0.86-28.35)$ & NS & & $11.3(1.03-124.9)$ & 0.047 \\
\hline & Available & $91(42.3)$ & & & & & & \\
\hline \multirow[t]{3}{*}{$\mathrm{PNI}^{*}$} & 0 & $54(39.7)$ & 136 & Ref & & 114 & Ref & \\
\hline & 1 & $82(60.3)$ & & $2.36(1.23-4.53)$ & 0.010 & & $2.57(1.25-5.30)$ & 0.010 \\
\hline & Available & $136(63.3)$ & & & & & & \\
\hline
\end{tabular}

Abbreviations: HR Hazard Ratio, 95\% Cl, 95\% Confidence Interval, SD Standard Deviation, GPS Glasgow Prognostic Score, mGPS modified Glasgow Prognostic Score, NLR Neutrophil/Lymphocyte Ratio, PLR Platelet/Lymphocyte Ratio, PI Prognostic Index, PNI Prognostic Nutritional Index, NS Not Statistical Significant ( $\mathrm{p}>0.05)$. ${ }^{\#}$ Colum percentage, *Weighted Cox regression models, "Model adjusted for gender, age at diagnosis, intravenous drug user, AIDS defining event, CD4 cell count and HIV-RNA undetectable. ${ }^{\$}$ For prognostic variables classification see Table 1.

from NHL diagnosis to blood testing was 18 days (interquartile range: $3-53$ days).

Score 0 was attributed to the majority of patients for NLR, while for PI and PNI most subjects were categorized as score 1. About half of patients were scored with 1 for GPS and mGPS, and with 0 for PLR. No associations were found between prognostic variables and HIVRNA copy number in subjects with positive HIV-RNA at NHL diagnosis. GPS, mGPS, PI and PNI were independently associated with risk of death using both univariate and multivariate Cox models. These results were also confirmed when we limited the analyses to patients under cART (data not shown).

The likelihood ratio tests for the global fit of the model, before and after addition of inflammatory variables to the full model, were significant for GPS, mGPS, PI and PNI $(\mathrm{p}<0.001)$.
Non-linear relationships between NLR, PLR, PNI and risk of death were evaluated by using multivariate Cox regression models with a restricted cubic-spline for each prognostic score (Figure 1). A trend of increasing risk of death with increasing PNI was observed, although not statistical significant, whereas no trend with PLR and NLR was found.

The ROC analysis showed that mGPS, GPS, PNI and PI had statistically significant discrimination ability, with AUC ranging from 0.60 to 0.69 , with follow-up truncated at both 3 and 5 years (Table 4).

\section{Mortality risk score}

Finally, we computed a risk score for death on the basis of the final Cox model. In the derivation sample (93 subjects with PNI available, 34 of which died), age, occurrence of an AIDS defining event within six months from 


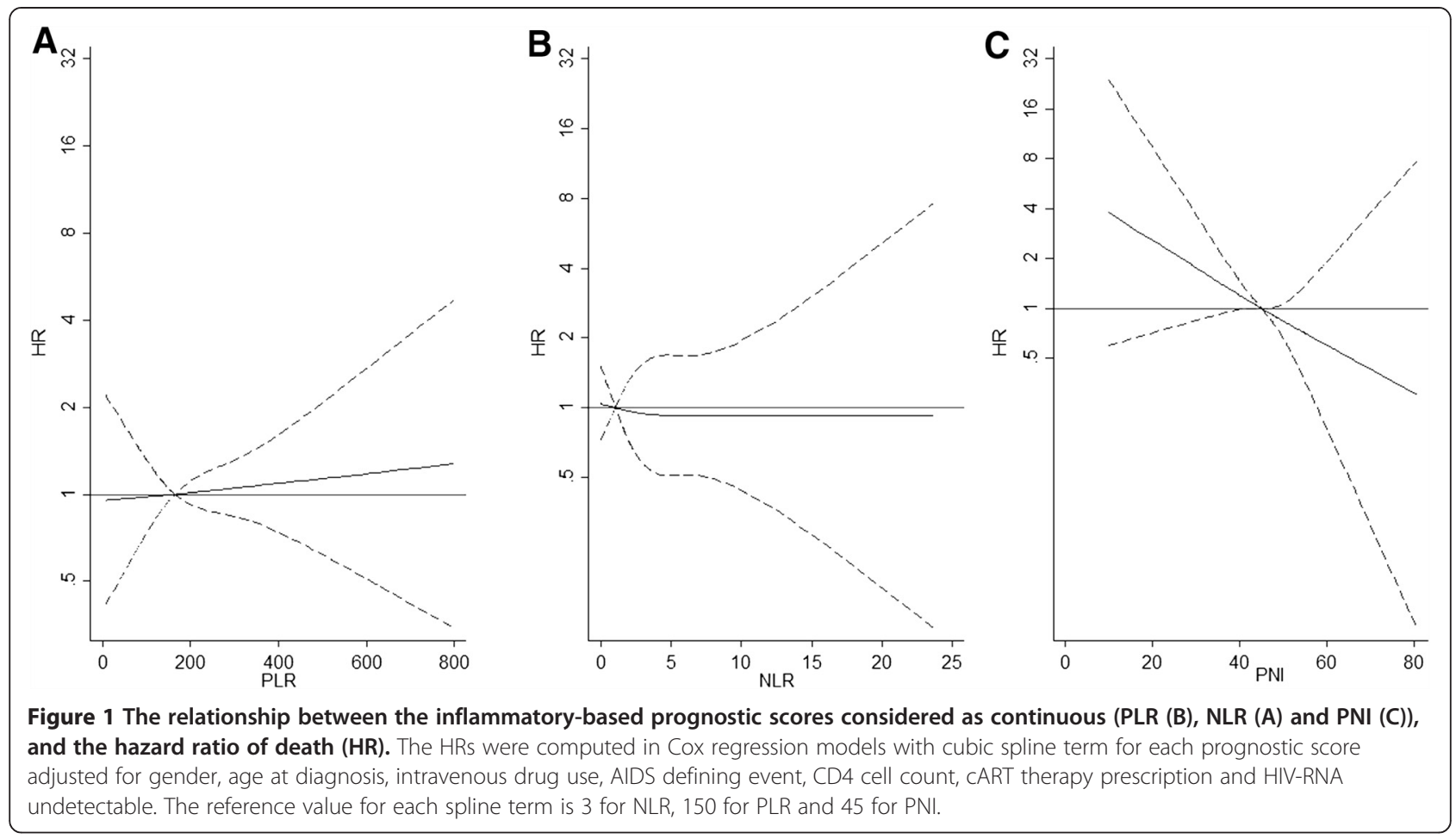

date of NHL diagnosis, no cART assumption, CD4 cell count lower than 200 cells $/ \mathrm{mm} 3$ and PNI equal to 1 were significantly associated with fatal outcome in univariate Cox regression analysis (Table 5). However, in multivariate analyses, only occurrence of AIDS defining event within 6 months from NHL diagnosis and PNI were independently associated with mortality, also using bootstrapping technique.

The linear prediction equation for risk of mortality $(\mathrm{Rm})$ derived from the final Cox model was: $\mathrm{Rm}=0.703$ *(occurrence of AIDS defining event within six months from NHL diagnosis $[$ yes $=1 /$ no $=0])+0.794^{*}(\mathrm{PNI})$. The

Table 4 Areas under the ROC curve using various prognostic variables

\begin{tabular}{lll}
\hline Prognostic variables & $\begin{array}{l}\text { Area under the ROC } \\
\text { curve at 3-year of } \\
\text { follow-up (95\% Cl) }\end{array}$ & $\begin{array}{l}\text { Area under the ROC } \\
\text { curve at 5-years of } \\
\text { follow-up (95\% Cl) }\end{array}$ \\
\hline GPS* & $\mathbf{0 . 6 7}(\mathbf{0 . 5 4 - 0 . 8 0 )}$ & $\mathbf{0 . 6 7}(\mathbf{0 . 5 4 - 0 . 8 0 )}$ \\
mGPS* $^{*}$ & $\mathbf{0 . 6 9 ( 0 . 5 6 - 0 . 8 2 )}$ & $\mathbf{0 . 6 6}(\mathbf{0 . 5 3 - 0 . 8 0 )}$ \\
NLR & $0.54(0.46-0.62)$ & $0.54(0.47-0.62)$ \\
PLR & $0.53(0.45-0.60)$ & $0.54(0.477-0.62)$ \\
PI $^{*}$ & $\mathbf{0 . 6 3 ( 0 . 5 3 - 0 . 7 3 )}$ & $\mathbf{0 . 6 0}(\mathbf{0 . 5 1 - 0 . 7 1 )}$ \\
PNI $^{*}$ & $\mathbf{0 . 6 5 ( 0 . 5 5 - 0 . 7 4 )}$ & $\mathbf{0 . 6 4}(\mathbf{0 . 5 5 - 0 . 7 4 )}$
\end{tabular}

Abbreviations: ROC Receiver Operating Characteristic, 95\% Cl 95\% Confidence Interval, GPS Glasgow Prognostic Score, mGPS modified Glasgow Prognostic Score, NLR Neutrophil/Lymphocyte Ratio, PLR Platelet/Lymphocyte Ratio, PI Prognostic Index, PNI Prognostic Nutritional Index.

The bold Areas under the ROC curves are those concerning variables resulted significantly predictive of death. predictive accuracies of this risk score for mortality, as measured by the AUC, were 0.69 (95\% CI 0.58 to 0.81 ) and 0.69 (0.57 to 0.81$)$ in derivation sample, and 0.69 (0.49 to 0.90 ) and 0.73 (0.53 to 0.92$)$ in validation sample (47 subjects with PNI available, 12 of which died), at 3 and 5 years of follow-up, respectively. As an application of the score, patients were categorized into three risk groups: patients without AIDS defining event within six months from the date of NHL diagnosis and with PNI > 45, patients with AIDS defining event within six months from the date of NHL diagnosis or with $\mathrm{PNI}<45$ and patients with AIDS defining event within six months from the date of NHL diagnosis and with $\mathrm{PNI}<45$. According to the 3 risk score categories, cumulative mortality rates were $20.8 \%$ (10.4 to 38.9 ), $31.8 \%$ (18.8 to 50.3 ) and $64.5 \%$ (43.3 to 84.8 ) in the low-, intermediateand high-risk group (log rank test $\mathrm{p}<0.001$ ) (Figure 2).

As a sensitive analysis, we have also computed a prognostic score including PNI and AIDS events on the whole cohort, finding AUCs for this score of 67.0 (56.377.6) and 67.9 (57.8-78.1) at 3 and 5 years, respectively.

\section{Discussion}

In this study, we investigated the relationship between some biomarkers of systemic inflammation and overall survival in HIV-infected patients with NHL for the first time. We found that some inflammatory-based scores including serum levels of CRP and albumin (GPS, mGPS, PI and PNI), but not those based on cellular 
Table 5 Cox regression analyses for mortality in the derivation sample

\begin{tabular}{|c|c|c|c|c|c|}
\hline \multirow[t]{3}{*}{ Variable } & \multirow[t]{3}{*}{ Category } & \multirow{2}{*}{\multicolumn{2}{|c|}{ Univariate analysis }} & \multirow{2}{*}{\multicolumn{2}{|c|}{$\begin{array}{l}\text { Multivariate analysis }^{\pi} \\
\text { n subjects included }=93\end{array}$}} \\
\hline & & & & & \\
\hline & & $\operatorname{HR}(95 \% \mathrm{CI})^{*}$ & $P$ value & HR $(95 \% \mathrm{Cl})^{*}$ & $P$ value \\
\hline Gender & Male vs Female & $1.03(0.59-1.79)$ & NS & & \\
\hline Age (years) & & $1.02(1.0-1.05)$ & NS & & \\
\hline IDU & Yes vs No & $1.04(0.66-1.66)$ & NS & & \\
\hline AIDS defining event & Yes vs No & $1.73(1.09-2.73)$ & 0.019 & $2.02(1.01-4.02)$ & 0.045 \\
\hline HBV or/and HCV co-infection & Yes vs No & $0.94(0.60-1.49)$ & NS & & \\
\hline CART & Yes vs No & $0.57(0.35-0.95)$ & 0.032 & & \\
\hline CD4 cell count, cell $/ \mathrm{mm} 3$ & $<200$ vs $\geq 200$ & $1.79(1.12-2.88)$ & 0.015 & & \\
\hline HIV-RNA undetectable & Yes vs No & $1.52(0.84-2.73)$ & NS & & \\
\hline PNI & $<45$ vs $\geq 45$ & $2.42(1.22-4.77)$ & 0.011 & $2.21(1.11-4.40)$ & 0.023 \\
\hline
\end{tabular}

Abbreviations: HR Hazard Ratio, 95\% CI 95\% Confidence Interval, IDU Intravenous Drug Use, HBV Hepatitis B Virus, HCV Hepatitis C Virus, CART combined Antiretroviral Therapy, PNI Prognostic Nutritional Index, NS Not Statistical Significant $(p>0.05)$.

${ }^{*}$ Adjusted for all the variables in the table. "The mortality risk score based on the regression coefficients of the variables in final model was represented by $0.703^{*}$ (AIDS defining event [yes $\left.\left.=1 / \mathrm{no}=0\right]\right)+0.794 *($ PNI) [AIDS defining event within six months from NHL diagnosis].

components of the white cell count (NLR and PLR), had an independent prognostic value for risk of death. We also computed a mortality risk score including PNI and occurring of an AIDS event within six months from NHL diagnosis, which showed a rather fair predictive ability, with an AUC of 0.69 at 3 years of follow-up.

Various prognostic parameters have been used for NHL, so far. Among them, the IPI is probably the most commonly used and it has been revised recently

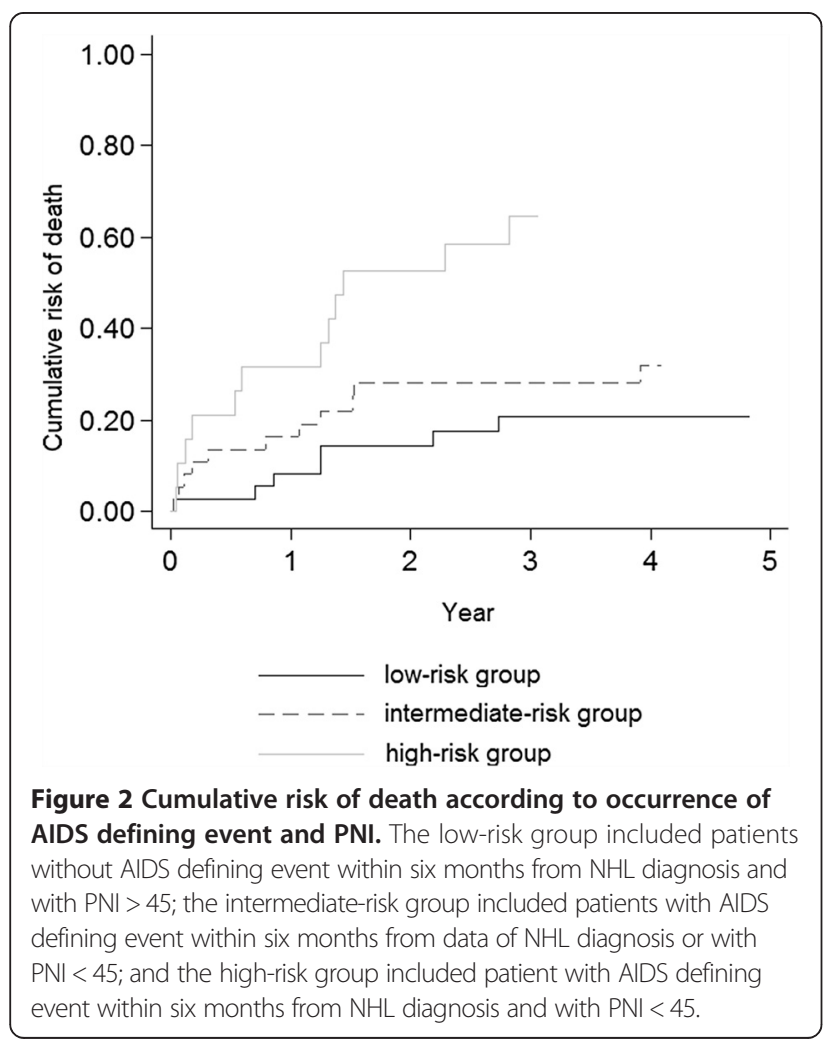

$[10,23,24]$. New inflammatory indexes, based on routinely examined blood parameters, have been proposed, including NLR and GPS: NLR has been found useful in patients with diffuse large B-cell lymphoma at low risk of death [18], whereas an elevated GPS was associated with poorer survival in patients with extranodal natural killer/T-cell lymphoma [19] and in those with diffuse large cell lymphoma treated with R-CHOP [17].

In HIV-infected patients with NHL, however, also HIV-infection related factors, such as cART, concurrent infections and baseline immunosuppression, have been found to influence prognosis $[4,7,25]$. However, the studies carried out so far produced inconsistent results. A low CD4 cell count at NHL diagnosis found to be an independent risk factor for death in pre-cART and early cART eras in two large cohorts [3-5,26], whereas history of AIDS was associated with worse survival only in the pre-cART era [4]. A protective effect of cART has been described $[27,28]$. Other studies, however, found that only patient- and lymphoma-, but not HIV-related factors were predictive of poor outcome in the cART era [7-9]. For this reason, a composite score for HIVinfected patients with NHL has been recently developed which involves both HIV infection factors and the variables included in IPI [29]. Nevertheless, the IPI is not of common use for HIV patients, because of lack of some necessary data, and other inflammatory scores based on routine data, such as NLR and GPS, may be considered.

In our study, we have included all HIV-infected patients with NHL independently of histology, Ann Arbor stage or chemotherapy regimen. The 2-year cumulative risk of death from NHL diagnosis in our cohort was $45 \%$ [1], slightly lower than the $50-70 \%$ value reported in previous studies on HIV-infected subjects $[4,5,26,30]$. This is possibly due to the fact that previous studies included 
patients with NHL diagnosis between the late 1990s and early 2000s, when both cART and chemotherapy regimens were not so effective as they are todays.

In these subjects, we found that some indexes including serum CRP and albumin (GPS and mGPS, PNI and $\mathrm{PI})$, as representative of systemic inflammation and nutrition status, were independent predictors of survival in HIV patients with NHL. Therefore, we developed a simple score which integrates clinical and laboratory variables for assessing risk of death in HIV-infected patients with NHL. The score includes one of the HIV-related variables, i.e. an AIDS defining event occurring within six months from NHL diagnosis, and one inflammatory score, the PNI, based on common blood parameters such as lymphocytes and albumin, which therefore can be easily applied to any patient with newly diagnosed NHL. We found that this score had a rather fair predictive ability with an AUC of 0.69 at 3 years of follow-up.

There are several strengths in our study, including a large sample size, multicenter national cohort and inclusion of patients receiving state of the art lymphoma and HIV care. This study has some limits, too. First, we could not analyze the prognostic factors according to type of NHL, due to lack of power of the study for subgroup analyses. Second, the derivation and validation samples used to compute and test the prognostic score were unbalanced (70\% and 30\%, respectively). In fact, because of the relatively small number of NHL cases, we choose to include more subjects (70\%) in the derivation cohort to get better precision of the estimates. Anyway, we also computed a prognostic score including PNI and AIDS events within six months from NHL diagnosis on the whole cohort, finding an AUC for this score similar to those computed using validation and derivation cohorts.

\section{Conclusions}

In summary, our study extends previous findings which were focused on solid cancers and shows that some markers of systemic inflammatory response are associated with poor outcome also in HIV-infected patients with NHL.

\footnotetext{
Abbreviations

NHL: Non-hodgkin lymphoma; CART: Combined antiretroviral therapy; IPI: International prognostic index; LDH: Lactate dehydrogenase; CRP: C-reactive protein; GPS: Glasgow prognostic score; NLR: Neutrophil/ lymphocyte ratio; PLR: Platelet/lymphocyte ratio; HBV: Hepatitis B virus; HCV: Hepatitis C virus; HCV: Viral hepatitis C; mGPS: Modified glasgow prognostic score; PI: Prognostic index; PNI: Prognostic nutritional index; HR: Hazards ratio; 95\% Cl: 95\% confidence interval; ROC: Receiver operating characteristic; AUC: Area under the receiver operating characteristic curve; SD: Standard deviation; Rm: Risk of mortality.

\section{Competing interests}

The MASTER Cohort and this study were funded by M.I.S.I. foundation (Fondazione Malattie Infettive e Salute Internazionale, http:// www.fondazionemisi.it/). The authors declare that they have no competing interests.
}

\section{Authors' contributions}

The authors participated meaningfully in the study. Specific author contributions were: Study concept and design: RE, QRE and DF; acquisition of data: CF, LN, PG, DFE, SD, CG, BA, ZF, DS, DPM, CF and QRE; analysis and interpretation of data: all author; drafting of the first version of the manuscript: RE, QRE and DF; critical revision of the manuscript for important intellectual content and approval of final version: all authors; statistical analysis: RE; study supervision: DF. All authors read and approved the final manuscript.

\section{Acknowledgements}

We thank Prof. Giampiero Carosi for his thoughtful review of the manuscript, the editor and the reviewers for their constructive comments, which helped us to improve the manuscript, and all patients, doctors, nurses and the dedicated staff of the local centers: Institute of Clinical Infectious Diseases of Spedali Civili Hospital, University of Brescia, Brescia; the Department of Infectious Diseases of San Gerardo de' Tintori Hospital, Monza; the Department of Infectious Diseases, Papa Giovanni XXIII Hospital, Bergamo; the Department of Infectious Diseases of Istituti Ospedalieri of Cremona, Cremona; Department of Infectious Diseases of Nuovo Polo Ospedaliero S.Anna di Cona, Ferrara; the Department of Infectious Diseases of Santa Maria Annunziata Hospital, Florence; the Institute of Clinical Infectious Diseases of Polyclinic A. Gemelli, University of Sacred Heart, Roma; the Institute of Clinical Infectious Diseases of Polyclinic of Bari, University of Bari, Bari.

\section{Author details}

${ }^{1}$ Unit of Hygiene, Epidemiology and Public Health, University of Brescia, Brescia, Italy. ${ }^{2}$ Hospital Division of Infectious and Tropical Diseases, Spedali Civili Hospital, Brescia, Italy. ${ }^{3}$ Department of Infectious Diseases, Polyclinic of Bari, University of Bari, Bari, Italy. ${ }^{4}$ University Division of Infectious and Tropical Diseases, University of Brescia, Brescia, Italy. ${ }^{5}$ Department of Infectious Diseases of Papa Giovanni XXIII Hospital, Bergamo, Italy. ${ }^{6}$ Department of Infectious Diseases, S. Anna Hospital, Ferrara, Italy. 7Department of Infectious Diseases, San Gerardo de' Tintori" Hospital, Monza, Italy. ${ }^{8}$ Clinical Infectious Diseases, Istituti Ospitalieri, Cremona, Italy. ${ }^{9}$ Institute of Clinical Infectious Diseases, Polyclinic A. Gemelli, University of Sacred Heart, Rome, Italy. ${ }^{10}$ Department of Infectious Diseases, SM. Annunziata Hospital, Florence, Italy.

Received: 6 December 2014 Accepted: 24 February 2015

Published online: 14 March 2015

\section{References}

1. Gotti D, Raffetti E, Albini L, Sighinolfi L, Maggiolo F, Di Filippo E, et al. Survival in HIV-infected patients after a cancer diagnosis in the CART Era: results of an Italian multicenter study. PLoS One. 2014;23:9(4).

2. Matthews GV, Bower M, Mandalia S, Powles T, Nelson MR, Gazzard BG. Changes in acquired immunodeficiency syndrome-related lymphoma since the introduction of highly active antiretroviral therapy. Blood. 2000;96(8):2730-4.

3. Robotin MC, Law MG, Milliken S, Goldstein D, Garsia RJ, Dolan GM, et al. Clinical features and predictors of survival of AIDS-related non-Hodgkin's lymphoma in a population-based case series in Sydney, Australia. HIV Med. 2004:5(5):377-84.

4. Bower M, Gazzard B, Mandalia S, Newsom-Davis T, Thirlwell C, Dhillon T, et al. A Prognostic Index for Systemic AIDS-Related Non-Hodgkin Lymphoma Treated in the Era of Highly Active Antiretroviral Therapy. Ann Intern Med. 2005;143(4):265-73.

5. Bohlius J, Schmidlin K, Costagliola D, Fatkenheuer G, May M, Caro Murillo AM, et al. Prognosis of HIV-associated non-Hodgkin lymphoma in patients starting combination antiretroviral therapy. AIDS. 2009;23(15):2029-37.

6. Hoffmann C, Hentrich M, Gillor D, Behrens G, Jensen B, Stoehr A, et al. Hodgkin lymphoma is as common as non-Hodgkin lymphoma in HIVpositive patients with sustained viral suppression and limited immune deficiency: a prospective cohort study. HIV Med 2014 Sep 23.

7. Lim ST, Karim R, Tulpule A, Nathwani BN, Levine AM. Prognostic factors in HIV-related diffuse large-cell lymphoma: before versus after highly active antiretroviral therapy. J Clin Oncol. 2005;23(33):8477-82.

8. Miralles P, Berenguer J, Ribera JM, Rubio R, Mahillo B, Tellez MJ, et al Prognosis of AIDS-Related Systemic Non-Hodgkin Lymphoma Treated With Chemotherapy and Highly Active Antiretroviral Therapy Depends Exclusively on Tumor-Related Factors. JAIDS. 2007;44(2):167-73. 
9. Lim ST, Karim R, Nathwani BN, Tulpule A, Espina B, Levine AM. AIDS-related Burkitt's lymphoma versus diffuse large-cell lymphoma in the pre-highly active antiretroviral therapy (HAART) and HAART eras: significant differences in survival with standard chemotherapy. J Clin Oncol. 2005;23(19):4430-8.

10. A predictive model for aggressive non-Hodgkin's lymphoma. The International Non-Hodgkin's Lymphoma Prognostic Factors Project. N Engl J Med. 1993; 329(14):987-94.

11. Grivennikov SI, Greten FR, Karin M. Immunity, inflammation, and cancer. Cell. 2010;140(6):883-99.

12. Roxburgh CS, McMillan DC. Role of systemic inflammatory response in predicting survival in patients with primary operable cancer. Future Oncol. 2010;6(1):149-63.

13. McMillan DC. The systemic inflammation-based Glasgow Prognostic Score: a decade of experience in patients with cancer. Cancer Treat Rev. 2013;39(5):534-40.

14. Guthrie GJ, Charles KA, Roxburgh CS, Horgan PG, McMillan DC, Clarke SJ. The systemic inflammation-based neutrophil-lymphocyte ratio: experience in patients with cancer. Crit Rev Oncol Hematol. 2013;88(1):218-30.

15. Templeton AJ, McNamara MG, Seruga B, Vera-Badillo FE, Aneja P, Ocaña A, et al. Prognostic role of neutrophil-to-lymphocyte ratio in solid tumors: a systematic review and meta-analysis. J Natl Cancer Inst. 2014;106(6):dju124.

16. Sun $\mathrm{K}$, Chen $\mathrm{S}, \mathrm{Xu} J, \mathrm{Li} \mathrm{G}, \mathrm{He} Y$. The prognostic significance of the prognostic nutritional index in cancer: a systematic review and metaanalysis. J Cancer Res Clin Oncol. 2014;140(9):1537-49.

17. Li X, Zhang Y, Zhao W, Liu Z, Shen Y, Li J, et al. The Glasgow Prognostic Score as a significant predictor of diffuse large B cell lymphoma treated with R-CHOP in China. Ann Hematol. 2015;94(1):57-63.

18. Troppan K, Deutsch A, Gerger A, Stojakovic T, Beham-Schmid C, Wenzl K, et al. The derived neutrophil to lymphocyte ratio is an independent prognostic factor in patients with diffuse large B-cell lymphoma. $\mathrm{Br} J$ Cancer. 2014;110(2):369-74.

19. Li YJ, Jiang WQ, Huang JJ, Xia ZJ, Huang HQ, Li ZM. The Glasgow Prognostic Score (GPS) as a novel and significant predictor of extranodal natural killer/T-cell lymphoma, nasal type. Am J Hematol. 2013;88(5):394-9.

20. Seaman SR, White IR. Review of inverse probability weighting for dealing with missing data. Stat Methods Med Res. 2013;22(3):278-95.

21. Harrell F. General Aspects of Fitting Regression Models. In: Regression Modeling Strategies - With Applications to Linear Models, Logistic Regression and Survival Analysis. New York: Springer-Verlag; 2011. p. 23-4

22. Akaike H. A New Look at the Statistical Model Identification. IEEE Trans Autom Control. 1974;AC-19(6):716-23.

23. Sehn LH, Berry B, Chhanabhai M, Fitzgerald C, Gill K, Hoskins P, et al. The revised International Prognostic Index (R-IPI) is a better predictor of outcome than the standard IPI for patients with diffuse large B-cell lymphoma treated with R-CHOP. Blood. 2007;109(5):1857-61.

24. Zhou Z, Sehn LH, Rademaker AW, Gordon LI, Lacasce AS, Crosby-Thompson A, et al. An enhanced International Prognostic Index (NCCN-IPI) for patients with diffuse large B-cell lymphoma treated in the rituximab era. Blood. 2014;123(6):837-42.

25. Simcock M, Blasko M, Karrer U, Bertisch B, Pless M, Blumer L, et al. Treatment and prognosis of AIDS-related lymphoma in the era of highly active antiretroviral therapy: findings from the Swiss HIV Cohort Study. Antivir Ther. 2007;12(6):931-9.

26. Chao C, Xu L, Abrams D, Leyden W, Horberg M, Towner W, et al. Survival of non-Hodgkin lymphoma patients with and without HIV infection in the era of combined antiretroviral therapy. AIDS. 2010;24(11):1765-70.

27. Barta SK, Xue X, Wang D, Tamari R, Lee JY, Mounier N, et al. Treatment factors affecting outcomes in HIV-associated non-Hodgkin lymphomas: a pooled analysis of 1546 patients. Blood. 2013;122(19):3251-62

28. Gopal S, Patel MR, Yanik EL, Cole SR, Achenbach CJ, Napravnik S, et al. Temporal trends in presentation and survival for HIV-associated lymphoma in the antiretroviral therapy era. J Natl Cancer Inst. 2013;105(16):1221-9.

29. Barta SK, Xue X, Wang D, Lee JY, Kaplan LD, Ribera JM, et al. A new prognostic score for AIDS-related lymphomas in the Rituximab-era. Haematologica. 2014;123(6):837-42.

30. Chow KU, Mitrou PS, Geduldig K, Helm EB, Hoelzer D, Brodt HR. Changing incidence and survival in patients with aids-related non-Hodgkin's lymphomas in the era of highly active antiretroviral therapy (HAART). Leuk Lymphoma. 2001;41:105-16.

\section{Submit your next manuscript to BioMed Central and take full advantage of:}

- Convenient online submission

- Thorough peer review

- No space constraints or color figure charges

- Immediate publication on acceptance

- Inclusion in PubMed, CAS, Scopus and Google Scholar

- Research which is freely available for redistribution

Submit your manuscript at www.biomedcentral.com/submit 